\title{
Regulación de la interpretación del Derecho Regulation of legal Interpretation
}

\author{
Álvaro Núñez Vaquero* \\ Universidad Austral de Chile \\ alvaro.nunez@uach.cl \\ alvaro.nunez.vaquero@gmail.com
}

Recibido / received: 25/08/2016

Aceptado / accepted: 15/09/2016

DOI: $\underline{\text { http://dx.doi.org/10.20318/eunomia.2016.3286 }}$

\section{Resumen}

El presente trabajo tiene por objetivo realizar una sucinta presentación de las diferentes formas en las que se puede regular la interpretación del derecho. Se comienza con un breve análisis acerca del (1) carácter de la regulación de la interpretación. A continuación se analizan (2) la regulación general de los métodos de interpretación, (3) las definiciones legales, (4) las leyes interpretativas, (5) la jurisprudencia y los precedentes y (6) los acuerdos vinculantes no jurisdiccionales provenientes de tribunales.

\section{Palabras clave}

Norma constitutiva, interpretación, métodos interpretativos, definiciones, jurisprudencia y precedentes.

\begin{abstract}
This paper aims to make a brief presentation of the different ways in which legal interpretation can be regulated. It begins with a brief discussion about (1) the interpretation regulation character. Next, (2) the general regulation of the interpretation methods, (3) legal definitions, (4) interpretive statutes, (5) jurisprudence and precedent, and (6) nonadjudicatory binding statements from courts are analyzed.

Keywords

Constitutive rule, interpretation, interpretive methods, definitions, jurisprudence and precedents.

SUMARIO. 1. Introducción. 2. El carácter de la regulación sobre la interpretación. 3. Regulación general del proceso de interpretación: métodos interpretativos. 4. Definiciones legales (o normativas). 5. Leyes interpretativas. 6 . Jurisprudencia y precedentes. 7. Normas de origen judicial no procedentes de la resolución jurisdiccional de casos.
\end{abstract}

\footnotetext{
* Este trabajo se enmarca dentro del proyecto de investigación Fondecyt "Realismo jurídico e indeterminación del derecho" ( $n^{\circ}$ 11130311) del Gobierno de Chile. El presente trabajo ha sido desarrollado en conjunto con María Beatriz Arriagada y Claudio Agüero. Aunque la firma es individual y tenemos algunos desacuerdos menores, es producto de un trabajo de reflexión conjunto.
} 


\section{Introducción}

La interpretación jurídica es una de las actividades más importantes del ámbito jurídico. No es de extrañar que la interpretación haya sido objeto de múltiples ensayos artículos y reflexiones de parte tanto de teóricos del derecho como de dogmáticos -civilistas y constitucionalistas especialmente, pero también de penalistas, administrativistas, entre otros-, quienes han tratado de arrojar luz sobre alguno de los aspectos de la interpretación. Los motivos son diversos, pero es posible aventurar que el primero y más importante es que la interpretación es una tarea constante en el trabajo de los juristas (al menos en algunos sentidos de "interpretación") y que ella está especialmente involucrada en la aplicación del derecho.

Es posible distinguir las teorías (en sentido estricto) que pretenden describir qué es la interpretación y/o cómo se interpreta, de las doctrinas o ideologías jurídicas que pretenden orientar a los operadores jurídicos sobre cómo se debe interpretar. La frontera, aunque clara desde un punto de vista conceptual, no siempre es sencilla de trazar en la práctica porque muchos de quienes sostienen que se debe interpretar el derecho de una determinada manera, suelen referirse al valor de la práctica jurídica efectiva, esto es, a cómo de hecho se interpretan los enunciados normativos.

Los estudios de la regulación normativa de la interpretación son igualmente difíciles de subsumir dentro de estas teorías y doctrinas de la interpretación, porque se ocupan del conjunto de normas que regulan cómo ha de interpretarse el derecho en el marco de un ordenamiento jurídico determinado. Dentro de este tipo de estudios son posibles dos aproximaciones diversas, con diferentes niveles de generalidad y abstracción: la primera de carácter (teórico-)general da cuenta de tales tipos de normas, pero sin detenerse en la regulación específica de ningún ordenamiento en particular; la segunda aproximación, de carácter dogmático (o propia de la ciencia del derecho), se ocupa del contenido de regulación específica sobre la interpretación en cada ordenamiento. Ambos tipos de estudios son ambivalentes en la medida en que pueden ser desarrollados mediante una aproximación normativa o descriptiva.

El presente trabajo se sitúa en la perspectiva de la teoría general de estas normas, sin detenerse en los pormenores de ningún ordenamiento. Además, se desarrolla desde un punto de vista meramente descriptivo.

Para analizar cada una de estas formas de regular la interpretación es necesario aclarar previamente qué se entenderá aquí por interpretación. Por 'interpretación' entenderé el acto (y/o el resultado) de atribución de significado a (uno o varios) enunciados normativos (o fragmentos de aquellos). Tal definición es solidaria con la distinción entre enunciados (o textos normativos) y normas (sentido de tales enunciados) (Pozzolo, 2011). Aunque no es el único concepto disponible de interpretación, es el más útil para analizar las diferentes formas de regular la interpretación debido a que es el único concepto disponible que no presupone ninguna tesis -ni normativa ni descriptiva- sobre el carácter de la actividad interpretativa (Diciotti, 1999).

2. El carácter de la regulación sobre la interpretación

Antes de ocuparnos de las formas de regular la interpretación, es conveniente detenerse brevemente en el carácter de tales normas. Ello debido a que algunos autores han considerado que no son normas en sentido estricto acerca de cómo 
debe realizarse la interpretación del derecho, sino únicamente de recomendaciones o consejos (véase sobre el punto Hernández Marín, 1994; Aguiló, 1990; Iturralde, 1989: 60). Detrás de esta tesis se encuentran al menos dos creencias diferentes que funcionarían como justificaciones de tal tesis (véase Guastini, 2004: 94). (1.1) La primera, de carácter normativo, afirma que la interpretación no debe ser regulada en abstracto, sino que debe ser una actividad llevada a cabo de manera libre por el aplicador del derecho (o por la dogmática jurídica). (1.2) La segunda de ellas tiene un carácter teórico y afirma: (1.2.1) en primer lugar, que los enunciados normativos sobre la interpretación no expresan (contingentemente, en un determinado ordenamiento) normas (solo meras recomendaciones), o, (1.2.2) en segundo lugar, que los enunciados normativos no son idóneos - esto es, no pueden o no sirven para expresar normas jurídicas.

Me detengo solo en esta última tesis (1.2.2), ya que la primera (1.1) es una cuestión de política jurídica, y la segunda (1.2.1) simplemente depende de las convenciones interpretativas de cada comunidad jurídica $y$, entonces, es contingente.

Rechazar la idea de que tales enunciados no son susceptibles de expresar normas jurídicas exige comprender en qué sentido aquellos pueden expresar normas. A tal fin es preciso distinguir entre dos tipos de normas: normas prescriptivas y constitutivas (Von Wright, 1970: 26 ss; Searle, 1997: 21 ss). Las "normas prescriptivas" son aquellas normas que correlacionan un tipo de acción (caso genérico) con una calificación deóntica (solución normativa): prohibido, obligatorio, permitido. Las "normas constitutivas" son normas que correlacionan tipos de acción con otros tipos de acciones (Moreso y Vilajosana, 2004: 73). Establecen, por así decirlo, qué es posible hacer válidamente dentro del juego del derecho. Pues bien, las diferentes formas de regular la interpretación encajarían con las normas constitutivas: antes que establecer prohibiciones, obligaciones o permisos -a las que normalmente van asociadas algún tipo de sanciones-, los enunciados normativos que expresan las normas sobre la interpretación determinan qué cuenta como una interpretación válida dentro de las reglas del juego del derecho. Tales normas establecen cuándo estamos frente a una interpretación perteneciente al juego de la interpretación jurídica y cuándo no. En tal sentido, antes que desencadenar una sanción, la consecuencia de su no observancia sería la invalidez. $\mathrm{Si}$ se superan dichas reglas del juego interpretativo, y no se considera que dichas interpretaciones son inválidas, estaremos frente a creación del derecho, en uno de estos dos sentidos: (1.a) en un sentido débil, cuando se aplica una regla interpretativa no prevista por el ordenamiento pero vigente en la comunidad jurídica; (1.b) en un sentido fuerte, cuando el resultado de la interpretación no constituye la aplicación de ningún criterio interpretativo vigente en la comunidad jurídica (no siendo en rigor un acto de interpretación, sino de creación intersticial de derecho).

Es preciso señalar que las normas constitutivas pueden verse acompañadas por normas prescriptivas que establezcan sanciones para quienes interpretan el derecho de manera diferente a lo previsto. Es más, es perfectamente posible interpretar los enunciados que formulan las normas sobre la interpretación de manera tal que expresen, al mismo tiempo, normas constitutivas $y$, complementariamente, normas prescriptivas. Lo que no parece plausible es pensar, como se ha hecho de manera tradicional por una parte de la literatura, que las normas interpretativas sean solo prescripciones.

La razón sale a la luz si se modifica ligeramente una tesis acerca de las normas de competencia de Atienza y Ruiz Manero (2004: 73 ss). En efecto, si las normas de interpretación delimitan el ámbito competencial de los jueces -aquellos 
solo tienen competencia para dictar sentencias válidas, y es condición necesaria de su validez que interpreten de conformidad a dichas normas sobre interpretación-, entonces cabe preguntarse qué estatus deóntico tendría una sentencia irregular, es decir, una decisión jurisdiccional que viola las normas sobre la interpretación jurídica, pero que aun así surte efectos jurídicos. Caben dos opciones sobre este punto. Si se opta por considerar que los órganos de adjudicación no tienen permiso para (o tienen prohibido) dictar sentencias que violen las normas de interpretación, entonces no podremos explicar por qué dichas sentencias, pese a ser irregulares, surten efectos jurídicos. Si, en cambio, se opta por considerar que tienen permiso para violar las normas sobre interpretación, entonces pareciera que estas normas son self-defeating, autocontradictorias, lo que resulta muy poco plausible. De este modo, no parece posible considerar que las normas sobre la interpretación puedan ser solo normas prescriptivas ${ }^{1}$.

Es posible que los enunciados que expresan las normas constitutivas sobre la interpretación, expresen también normas prescriptivas que prevén sanciones. Ello no implica que tales normas constitutivas sean irrelevantes en caso de no ir acompañadas de normas prescriptivas (y sus respectivas sanciones), sino que delimitan el ámbito de aquello que es posible hacer dentro del derecho. Aunque su no-seguimiento pueda estar exento de sanción, lo cierto es que las decisiones que no siguen las normas sobre interpretación podrían ser consideradas como decisiones inválidas (anulables).

De este modo, tendremos una regulación sobre la interpretación cuando contemos al menos con una norma constitutiva sobre la interpretación que delimita el ámbito de las interpretaciones válidas. Ahora bien, ¿la presencia solo de normas prescriptivas es suficiente para considerar que existe una regulación de la interpretación? La respuesta es negativa: si la violación de esa norma solo tuviera efectos sancionadores contra el intérprete, sin generar ningún efecto de anulabilidad sobre la decisión dictada con base en una interpretación proscrita o prohibida ${ }^{2}$, entonces el juez tendría todavía la posibilidad de optar entre dos interpretaciones posibles, ambas válidas en ausencia de norma constitutiva que delimite el ámbito del derecho válidamente producido. Ello seguiría siendo así incluso aunque una de dichas interpretaciones trajera aparejada una sanción.

Antes de analizar las diferentes formas en las que regular la interpretación, es conveniente distinguir entre dos técnicas diferentes para regularla, dependiendo de qué es exactamente lo que se regula. Al designar el vocablo "interpretación" tanto el acto de interpretación como su producto, la normativa sobre la interpretación puede constituir tanto una normativa sobre (a) el proceso de interpretación como (b) sobre el resultado de la interpretación. En el primer caso, (a) lo que se regula es

\footnotetext{
1 Es preciso señalar que estoy presuponiendo que las nociones de norma prescriptiva, constitutiva y técnica, constituyen una clasificación exhaustiva y excluyente de los tipos de normas. Mi argumento en este sentido, además del mencionado efecto de invalidez o anulabilidad, presupone que al no tratarse de normas prescriptivas, se trata de normas constitutivas. En este sentido habría sido necesario eliminar la posibilidad de que se trate de normas técnicas, pero el espacio limitado de este trabajo impide dar cuenta de dicha cuestión. A modo de extrema síntesis, es posible afirmar que las normas técnicas presuponen relaciones de causalidad (y/o enunciados anankásticos), y no veo cómo las reglas de interpretación podrían presuponer relaciones de este tipo. No parece en este sentido que el uso de las reglas interpretativas garanticen la consideración como válida de una interpretación por parte de la comunidad jurídica porque

${ }^{2}$ Algo similar se puede decir cuando hay solo una norma que considera obligatoria una sola interpretación, debido a la interdefinibilidad entre prohibido y permitido. No obstante, es preciso señalar que resulta poco frecuente que un ordenamiento tenga solo normas interpretativas de prohibición, siendo más habitual que tenga normas que obligan a seguir determinadas interpretaciones. Menos frecuente aún resulta que solo contenga normas permisivas. Ello debido a que los permisos expresos o fuertes no servirían para orientar demasiado el comportamiento interpretativo.
} 
cuáles son los instrumentos que se pueden usar para interpretar, mientras que en el segundo (b) lo que se regula es qué resultado interpretativo (norma) al que se debe llegar.

3. Regulación general del proceso de interpretación: métodos interpretativos En los sistemas de civil law, especialmente aquellos en los que la codificación jugó un papel importante, se han positivizado normas acerca de la interpretación en los códigos civiles (Tarello, 2013: cap. VI; Guzmán Brito, 2011). Lo más característico de este tipo de regulaciones de la interpretación es que no regulan el resultado de la interpretación, sino los instrumentos interpretativos.

Por "métodos interpretativos", "instrumentos interpretativos" o "técnicas interpretativas" aquí entenderé el conjunto de las reglas lingüísticas que permiten atribuir significado a los enunciados (directivas interpretativas de primer orden), y de las meta-reglas acerca del uso de las anteriores (directivas interpretativas de segundo orden). Las reglas lingüísticas están compuestas, en el derecho, por dos subconjuntos: las reglas del lenguaje natural y las reglas propias del discurso jurídico.

La regulación de la interpretación hace fundamentalmente dos cosas. La primera es fijar el conjunto de reglas que se pueden usar para atribuir significado a los enunciados normativos: interpretación literal, intencionalista, de acuerdo al espíritu, etc. (reglas lingüísticas o directivas interpretativas de primer orden). La segunda es establecer, a través de las meta-reglas (directivas de segundo orden), una jerarquía u orden interno en el empleo de las reglas de interpretación. Analicemos cada uno de estos aspectos por separado.

(2.1) En relación a la positivización de directivas interpretativas de primer orden surgen dos problemas (Chiassoni 2011: 80 ss; Guastini, 2004: cap. X; Núñez Vaquero 2016a; Tarello, 2011: 272 ss; Wroblewski 2008: 178 ss). (2.1.1) El primero es si se trata de listas exhaustivas de técnicas interpretativas allí positivizadas, o si se trata meramente de listas ejemplificativas. (2.1.2) El segundo de ellos es la imprecisión de la lista: frecuentemente la codificación emplea genéricas referencias al uso natural del lenguaje, a la coherencia, a la intención de la ley, a la intención del legislador, etc. El problema es que tal regulación no parece hacerse cargo de que el lenguaje natural es mucho menos preciso de lo que parece, que por coherencia podemos entender cosas diferentes, que el espíritu de la ley o de la legislación es una metáfora, o que podemos imputar diferentes tipos de intenciones al legislador.

El anterior problema refleja otro de carácter más general: para establecer qué ordenan las normas acerca de la interpretación, es necesario interpretar los enunciados que las expresan, produciéndose la paradoja (círculo vicioso) de que serían aplicables también a los enunciados que las positivizan. Dicho problema es en ocasiones afrontado a través de una interpretación originaria o de una literal (Guzmán Brito 1992; Bascuñán, 2013), pero no hay ninguna razón jurídica para interpretar de tales maneras los enunciados sobre la interpretación.

(2.2) Es posible distinguir entre cuatro tipos de directivas de segundo orden (o directivas interpretativas de segundo orden): (i) aquellas que establecen una prohibición de usar alguna regla interpretativa (i.e. prohibido desviarse del sentido literal de las palabras); (ii) aquellas que establecen una preferencia absoluta de un método frente a otros (i.e. prefiérase siempre la interpretación coherente con el resto de normas del ordenamiento); (iii) aquellas que establecen una preferencia relativa de un método frente a otros (i.e. prefiérase la interpretación original, salvo si produce resultados absurdos); y (iv) las cláusulas de cierre del sistema, es decir, aquella 
norma que establece el criterio a aplicar de manera subsidiaria (i.e. en caso de dudas interpretativas, recúrrase al espíritu general de la legislación).

Pues bien, lo que hacen las directivas interpretativas de segundo orden es crear una jerarquía en la aplicación de las reglas interpretativas de primer nivel. Los problemas fundamentales que surgen aquí son dos: (2.2.1) identificar las metanormas y (2.2.2) las reglas de preferencia entre las metanormas. En relación a este último punto, el problema es que -estando todas las directivas de segundo orden en el mismo nivel- faltan directivas de tercer orden que establezcan las relaciones de preferencia entre las directivas de segundo orden. En la mayoría de ordenamientos que tienen regulaciones generales sobre la interpretación, no suele existir acuerdo sobre las reglas de preferencia entre las directivas interpretativas de segundo orden $^{3}$.

(2.3) Además de los problemas ya señalados, la normativa general sobre la interpretación enfrenta un problema ulterior: su alcance. En la tradición del civil law esta regulación está positivizada en el respectivo código civil, frecuentemente bajo el epígrafe "interpretación de la ley" ". Surgen así dos preguntas. (2.3.1) En primer lugar, qué hay que entender por "ley": ¿solo aquellas expresamente llamadas "ley", todas aquellas con el mismo rango jerárquico, o todos los enunciados normativos (incluidos los jerárquicamente superiores)? (2.3.2) En segundo lugar, el posible efecto retroactivo de dichas normas, es decir, si son aplicables a normas previas a su promulgación.

\section{Definiciones legales (o normativas)}

La segunda forma en la que es posible regular la interpretación del derecho es mediante el uso de definiciones legislativas, normativas o legales, es decir, enunciados lingüísticos que establecen relaciones de sinonimia entre dos enunciados (Guastini, 2004: cap. III; Pérez Carrillo, 1974; Hernández Marín, 1994; Scarpelli, 1985). Antes de seguir, es preciso subrayar que aquí me refiero exclusivamente a las definiciones legales, y no a aquellas formuladas por la ciencia o dogmática jurídica (Núñez Vaquero, 2016b). Es importante recalcar esta idea porque las definiciones legislativas guardan una profunda relación con las definiciones o conceptos elaborados por la dogmática jurídica (Tarello, 2011: cap. IV). Ello porque es frecuente que la dogmática considere como poco satisfactorias algunas definiciones, reformulándolas por otras más sofisticadas 0 , incluso, ignorándolas directamente ${ }^{5}$.

Las definiciones legales no nos dicen cómo ha de realizarse la interpretación, sino directamente qué resultado o producto interpretativo se debe alcanzar: qué significado debemos atribuir a un término, qué norma debemos derivar de un

\footnotetext{
${ }^{3}$ Ello quiere decir que no se ponen de acuerdo acerca de cuáles son las meta-directivas de interpretación. Sin embargo, es posible que aunque los intérpretes no se pongan de acuerdo en la interpretación en abstracto, todos interpreten convencionalmente de la misma manera enunciados normativos en concreto. Ahora bien, no hay ninguna necesidad en esta última posibilidad. Es más, es posible (y frecuente) que dichos desacuerdos se reproduzcan a la hora de emplear la regulación de la interpretación; o, incluso, que dichas normas sean directamente ignoradas o mencionadas solo retóricamente.

${ }^{4}$ Denominaciones similares aparecen en los vigentes códigos civiles italiano (art. 12 preleggi), portugués (arts. 9 ss) chileno (arts. 19-24), argentino (art. 2), portoriqueño (arts. 14 ss) y colombiano (arts. 25 ss), entre otros. Otros códigos, como el español, hablan de la interpretación de las "normas" que si bien evitan el primer problema, incurre en el segundo tipo de problemas.

${ }^{5}$ No faltan en absoluto los ejemplos de términos jurídicos definidos legalmente que son sencillamente ignorados tanto por la jurisprudencia como por la dogmática. Resulta especialmente significativa la definición de delito incorporada el Código Penal Chileno (art. 1).
} 
enunciado ${ }^{6}$. No obstante, es frecuente que las normas generales sobre la interpretación regulen -tanto a través de reglas interpretativas de primer orden como de segundo orden- el uso de las definiciones legales. Sin embargo, no es imposible el uso de definiciones legislativas por parte del legislador sin que sean contempladas en la regulación de la interpretación, o incluso sin regulación general sobre la interpretación.

Las definiciones legales afrontan algunos problemas para su aplicación. (3.1) El primero de ellos es que al tratarse de definiciones, y por tanto de enunciados lingüísticos, están sujetos a interpretación. De este modo, tienen los mismos problemas de interpretación que debe afrontar cualquier enunciado al que atribuir significado: ambigüedad del enunciado y vaguedad de los posibles significados.

(3.2) El segundo problema que enfrentan las definiciones legales es su extensión: a qué otros enunciados normativos es aplicable la definición legislativa. Es posible distinguir ulteriormente entre dos tipos de problemas diferentes a este respecto. (3.2.1) En primer lugar, en relación a los textos normativos que expresan normas situadas en el mismo nivel jerárquico que las definiciones normativas, surge el problema de a qué textos es aplicable la definición normativa: ¿únicamente al texto normativo en el que aparecen (intratextual) o también para otros textos (intertextual)? (3.2.2) En segundo lugar, en relación a textos normativos que expresan normas de diferente nivel jerárquico, es posible preguntarse si aquellas son aplicables a normas de rango jerárquico superior, o a normas provenientes de órganos con competencias descentralizadas o autónomas.

(3.3) El tercer problema es aquel relativo al posible efecto retroactivo de dichas normas. En efecto, si la norma define un término empleado en textos normativos previos a la norma definitoria, surge inmediatamente la pregunta acerca del posible efecto retroactivo de las mismas.

(3.4) El cuarto y último problema se refiere a la posible contradicción entre normas definitorias y otras normas. Baste un ejemplo: según la norma N1, la compra-venta es el contrato que permite la transmisión de la propiedad de un bien material a cambio de un precio; según la norma N2, la propiedad se transmite con el mero acuerdo de voluntades en la compra-venta de bienes inmateriales.

Sobre este tipo de contradicción entre normas es preciso señalar dos cosas. (3.4.1) La primera es que no está claro en qué sentido las anteriores normas estarían en contradicción, debido a que no tienen el mismo antecedente. El uso de ambas normas produciría, no obstante, una anfibología si las dos normas son empleadas en un mismo razonamiento ${ }^{7}$. (3.4.2) El segundo es que al tratarse con frecuencia de normas situadas en el mismo texto y emanadas al mismo tiempo, no parece que ninguno de los criterios generales de resolución de antinomias sean aplicables.

\section{Leyes interpretativas}

El siguiente tipo de normativa sobre la interpretación tiene por objeto -no ya el proceso interpretativo, sino- el resultado de la interpretación. Se trata de una forma

\footnotetext{
${ }^{6}$ Si consideramos que la interpretación es la atribución de sentido a enunciados completos, entonces las definiciones legales regularían el procedimiento, y no el resultado, porque harían referencia a un paso intermedio -atribuir sentido solo a un término- en el proceso interpretativo (de enunciados completos). Lo que me interesa señalar es que las definiciones normativas no son normas que indican qué instrumento o medio hay que usar para dotar de significado a un término, sino que establece una relación de sinonimia directa.

7 Agradezco a Giovanni Battista Ratti por haberme aclarado este punto.
} 
de regular la interpretación similar a las definiciones legislativas precisamente por regular el resultado de la interpretación, pero difiere de la anterior al menos por tres razones. En primer lugar, los sistemas de fuentes de muchos ordenamientos prevén expresamente la figura de la ley interpretativa (o reglamento interpretativo). En segundo lugar, las leyes interpretativas tienen un alcance mucho más delimitado que las definiciones interpretativas. La razón es que una definición interpretativa no se refiere a ningún particular enunciado normativo, sino a un término (o sintagma) que puede aparecer en diferentes textos. Por el contrario, cuando estamos frente a una ley interpretativa, la aplicabilidad de las normas se limita, al menos en principio, al texto identificado objeto de interpretación. En tercer lugar, mientras que las definiciones interpretativas aparecen intercaladas en textos normativos de mayor alcance, las leyes interpretativas normalmente solo contienen normas sobre la interpretación. No obstante, no es infrecuente que se aproveche para introducir normas de carácter no-interpretativo en leyes interpretativas.

Las leyes de interpretación son productos de acto de interpretación auténtica. Lo son, en efecto, pero no en el sentido de que necesariamente el autor del texto sea el mismo que emane la norma interpretativa. Ello, en primer lugar, porque en la mayoría de casos se trataría de una ficción, puesto que raramente el mismo sujeto que redacta la norma es quien redacta también la ley interpretativa (Guastini, 2004: 89 ss). En segundo lugar, porque en muchos ordenamientos, órganos diferentes a los que emanaron la norma objeto de interpretación pueden dictar normas interpretativas: especialmente la constitución (obra del poder constituyente) y las leyes de interpretación constitucional (producidas por poderes constituidos). Las leyes interpretativas son efectivamente el resultado de ejercicio de interpretación auténtica, pero en el sentido kelseniano de interpretación dotada de valor normativo (Kelsen, 2005: 354).

Dentro de las leyes interpretativas es necesario distinguir entre las leyes de interpretación propia e impropia (Tarello, 2011: 253-254). Las leyes de interpretación impropias son aquellas que vienen a sustituir el texto interpretado por un texto nuevo, mientras que las leyes de interpretación propias no sustituyen el texto objeto de interpretación, sino que únicamente fijan normativamente su significado.

(4.1) Las impropias pueden ser equiparadas sin más a normas derogatorias. Nótese que si todas las leyes interpretativas fueran impropias y tuvieran efectos derogatorios, entonces toda ley interpretativa tendría la misma fuerza activa (capacidad de derogar otros textos) que la ley interpretada, pero no la misma fuerza pasiva (resistencia a la derogación) que la norma que interpreta (Guastini, 2016: cap. XX). Ello al menos en el caso de que la ley interpretativa tenga un procedimiento diferente para su creación, por tener unas exigencias de mayoría diversas, o porque la competencia para su creación corresponda a un órgano diferente.

(4.2) Las leyes interpretativas propias pueden tener diferente naturaleza, dependiendo de si se les atribuye o se considera que tienen un carácter meramente declarativo o un carácter constitutivo. Si se considera que las leyes interpretativas propias únicamente aclaran el significado de una norma (carácter declarativo), cumpliendo una función meramente epistémica (Atienza y Ruiz Manero, 2004: 97), entonces pareciera que necesariamente deberían tener efecto retroactivo porque toda decisión previa basada en una interpretación diferente del enunciado normativo sería una interpretación incorrecta o inválida. Si, por el contrario, se considera que las leyes interpretativas propias tienen carácter constitutivo, entonces el efecto sería similar a las de una sentencia interpretativa de aceptación, derogando el resto de 
interpretaciones que pudieran ser derivadas del texto objeto de interpretación (Guastini, 2004: 91 ss) hacia el futuro.

Es preciso subrayar que si las leyes interpretativas (tanto impropias como propias de carácter constitutivo) tuvieran efecto derogatorio sobre el texto objeto de interpretación, aquellas tendrían la misma fuerza activa que la norma interpretada. Pero, si así están las cosas, entonces parecería evidente que habría diferentes formas para la modificación de un mismo texto normativo: el procedimiento estándar y el procedimiento mediante ley interpretativa. Este punto genera problemas especialmente en relación a las leyes de interpretación constitucional, presentes en un buen número de ordenamientos, y que suelen requerir mayorías menores para su aprobación (Zúñiga Urbina, 2009).

La otra opción, considerar todas las leyes interpretativas como propias de carácter declarativo, tampoco parece muy convincente (Guastini, 2004: cap. IV). La razón es que estaría en contra de cualquier teoría no férreamente cognitivista de la interpretación, que considera aquella como un acto meramente de conocimiento, pero que es la teoría de la interpretación que goza de menor predicamento hoy en día. En efecto, tanto para las teorías escépticas como moderadas, si un texto requiere de aclaración, entonces se estaría creando derecho nuevo con algún margen de discrecionalidad.

Más allá de los problemas relativos a cada una de estas formas de considerar las leyes interpretativas, surgen una serie de problemas comunes a ambos tipos. (4.a) El primero es la interpretación de la propia ley interpretativa. Resulta, en este sentido, ingenuo pensar que las leyes interpretativas eliminan el margen de discrecionalidad del intérprete: en primer lugar, porque antes que eliminar la interpretación, cambia el objeto de la misma; en segundo lugar, porque la virtualidad resolutiva de la ley depende de cómo esté redactada la ley interpretativa. (4.b) El segundo problema es la identificación del texto objeto de interpretación. Desde luego, lo más frecuente es que la propia ley interpretativa identifique formalmente el texto objeto de interpretación. Sin embargo, no ha de descartarse que se produzcan errores de identificación y/o transcripción. (4.c) Un tercer problema se produce por la derogación formal del texto normativo objeto de interpretación. Parecería en estos casos que lo más sensato es pensar que la norma interpretativa pierde su eficacia (entendida como capacidad de generar efectos jurídicos), aunque no su validez. Sin embargo, en ocasiones la misma expresión empleada en el texto objeto de interpretación por la ley interpretativa aparece de nuevo en un texto que viene a sustituir el texto derogado ${ }^{8}$. Cuál sea el valor jurídico de la ley interpretativa que tiene por objeto un texto derogado, pero que interpreta una expresión positivizada en un nuevo texto, no es cuestión que tenga una solución general más allá de lo previsto por cada ordenamiento.

\section{Jurisprudencia y precedentes}

Otra de las formas más habituales para regular la interpretación son los precedentes (Iturralde, 2014; Núñez Vaquero, 2016c). Los "precedentes" o la "jurisprudencia vinculante" son las decisiones jurisdiccionales a las que se les atribuye un determinado valor para decidir los casos diferentes (Núñez Vaquero, 2016c). Si bien no son dos fenómenos idénticos (Taruffo, 2009: caps. 33-35) -aunque tampoco hay homogeneidad en todo lo que llamamos respectivamente precedente $y$

\footnotetext{
${ }^{8}$ Por ejemplo, la Ley de interpretación constitucional 18.152 de Chile interpreta tanto la Constitución vigente al momento de su emanación, así como aquella de 1925. Ambas constituciones contenían un mismo enunciado normativo, y no sería descabellado pensar que el mismo enunciado volviera a aparecer en una constitución posterior.
} 
jurisprudencia vinculante (Falcón y Tella, 2010)-, aquí los consideraré como instancias o ejemplos de un mismo tipo de regulación de la interpretación: su regulación a raíz de la resolución de un concreto caso (caso individual).

No se trata de que toda la decisión jurisdiccional sea vinculante ${ }^{9}$, sino alguna parte de ella, normalmente denominada ratio decidendi, y opuesta al obiter dicta, la parte no vinculante de la sentencia ${ }^{10}$. Sin embargo, qué parte de la decisión judicial sea la ratio decidendi es una cuestión controvertida. Aquí no es necesario dar cuenta de todas las tesis acerca de qué parte de la sentencia puede constituir la ratio decidendi (Chiassoni, 2012), sino que es suficiente con establecer que es posible hablar de rationes decidendi interpretativas (Igartua, 2006; Laporta, 1997).

La ratio decidendi interpretativa es aquella norma aplicada por un tribunal en el contexto de la decisión de un caso- para atribuir significado a un determinado enunciado o conjunto de enunciados normativos, derivando así una norma empleada en el razonamiento que aparece en la justificación interna o externa de la sentencia. Dicha norma puede tener dos contenidos diferentes: a) una norma interpretativa sobre qué instrumento debe ser empleado para interpretar un enunciado (o conjunto de enunciados), o bien b) una norma acerca de qué resultado interpretativo debe ser alcanzado cuando se interpreta un concreto enunciado.

Los precedentes interpretativos generan problemas similares al resto de formas de regular la interpretación. También causan problemas semejantes a los que afectan el uso de cualquier tipo de precedente. Me limito a mencionar los dos más importantes. (5.1) El primer problema que debe afrontar el uso de precedentes interpretativos es que, al estar plasmados en sentencias judiciales, y siendo aquellas conjuntos de enunciados lingüísticos, enfrentan problemas de interpretación similares a los enunciados normativos de origen legislativo ${ }^{11}$.

(5.2) El segundo tipo de problemas que enfrenta el uso de precedentes interpretativos es, como ya se ha mencionado, que las normas acerca de cuán vinculantes son los precedentes suelen ser, en muchos ordenamientos, normas implícitas. También es frecuente que el sistema de precedentes sea lagunoso. Ello dificulta establecer en qué consiste exactamente la obligación de seguir el precedente interpretativo y a quién corresponde. Hay que añadir que es muy frecuente admitir que los precedentes no son nunca absolutamente vinculantes, y que en realidad los jueces tienen una amplísima gama de posibilidades para evitar la aplicación de los precedentes (Marshall, 1993; Núñez Vaquero, 2016c).

\footnotetext{
$9 \quad$ Las decisiones jurisdiccionales tienen valor de precedente interpretativo sencillamente cuando haya una norma que diga que son obligatorios (regla del stare decisis): una norma (o conjunto de normas) que señala determinadas decisiones o tipo de decisiones como normas válidas (y/o aplicables) para otros casos. No obstante, es preciso señalar que tales normas no son siempre normas expresas o formuladas, sino que con mucha frecuencia son normas implícitas, producto de la concreción de diferentes principios o producto de la construcción jurídica.

${ }^{10}$ No obstante, es preciso señalar que la relación entre obiter dictum y ratio decidendi es dinámica en un doble sentido: en primer lugar, porque qué parte sea obiter y cuál ratio de una misma sentencia puede cambiar a lo largo del tiempo por las diferentes interpretaciones que reciba la decisión jurisdiccional; en segundo lugar, no es infrecuente que se hable de obiter dicta vinculantes, es decir, un tercer tertium datur.

1 Si bien en nuestro contexto cultural se ha prestado una menor atención a los problemas relativos a la interpretación de sentencias, aquellos son conocidos desde hace tiempo (Llewellyn, 1950; Radin, 1946; Núñez Vaquero, 2016c).
} 
7. Normas de origen judicial no procedentes de la resolución jurisdiccional de casos

Consideración aparte merecen las normas interpretativas dictadas por órganos jurisdiccionales, pero que no son formuladas a raíz de la solución de ningún caso genérico o individual: son dictadas al margen de cualquier procedimiento para la resolución de litigio alguno. Estas normas podrían equipararse tanto a los precedentes como a las leyes interpretativas, y encuentran una de sus mejores expresiones en los acuerdos no jurisdiccionales del Pleno del Tribunal Supremo español (Manjón-Cabeza, 2008) y en los Autos acordados de la Corte Suprema chilena (Zuñiga Urbina, 2011). Se trata de enunciados normativos dictados por órganos de adjudicación que fijan el resultado interpretativo a alcanzar en relación a un enunciado normativo o conjunto de enunciados ${ }^{12}$.

Es preciso no confundir este fenómeno con otro similar, vinculado a los precedentes judiciales. En efecto, debido a los problemas para identificar la ratio decidendi de las decisiones jurisdiccionales, algunos ordenamientos han optado -en lugar de dejar la tarea a las revistas especializadas, a repertorios de sentencias o a cada juez la decisión de cuál es la ratio- por crear órganos especializados en fijar la ratio de las decisiones jurisdiccionales, o asignarle tal tarea a tribunales. Ejemplo excelente del primer tipo son las massime del Ufficcio del massimario de la Corte di Cassazione italiana, que tiene por función no la creación autónoma de normas interpretativas, sino fijar rationes decidendi provenientes de la propia Corte (Taruffo, 2009: 35§). Ejemplo del segundo tipo son las súmulas vinculantes que pueden dictar algunos órganos jurisdiccionales en Brasil, y que fijan -mediante un acto que no decide la calificación jurídica de ningún caso individual o genérico- la ratio decidendi de un caso o conjunto de casos previos (Zanetti Jr., 2015: cap. II) ${ }^{13}$. Fenómenos similares se pueden encontrar en otros ordenamientos, como la Corte Suprema chilena, que actualmente se encuentra en un proceso de sistematización de su propia jurisprudencia, seleccionando las rationes decidendi de un gran grupo de sentencias.

Sin embargo, ambos tipos de fenómenos (acuerdos no jurisdiccionales, por un lado, y súmulas y massime, por el otro) enfrentan problemas de interpretación similares a los de cualquier otro enunciado lingüístico: ambigüedad del texto y vaguedad de algunos significados. Finalmente, también son discutibles los posibles efectos derogatorios o retroactivos de dichas normas.

Bibliografía

AGUILÓ, J. (1990), "Sobre 'Definiciones y normas", en Doxa. Cuadernos de Filosofía del Derecho, núm 8, pp. 273-282.

ATIENZA, M. y RUIZ MANERO, J. (2004), Las piezas del derecho, Ariel, Barcelona.

\footnotetext{
${ }^{12} \mathrm{Ni}$ todos los Autos acordados españoles ni todos los Acuerdos no jurisdiccionales españoles son normas sobre la interpretación. Solo algunos de ellos. No obstante, también pueden surgir dudas acerca de cuándo estamos frente a Autos o Acuerdos interpretativos o frente a la formulación de normas completamente nuevas.

13 No obstante, hay que precisar que ya ha habido una súmula vinculante (la n. ${ }^{\circ} 11$ del Supremo Tribunal Federal de Brasil) que no fija la ratio decidendi de ninguna decisión jurisdiccional previa, sino que fue dictada con carácter independiente a cualquier proceso judicial sobre el tema. Si así están las cosas, esta súmula podría ser asimilada a un Acuerdo no jurisdiccional español o a un Auto acordado chileno. Debo agradecer a Clayton Maranhão, Tiago Alberto y Christian Delgado por su generosidad al haberme explicado con gran claridad en que consiste el fenómeno de las súmulas en el ordenamiento brasileño.
} 
BASCUÑÁN RODRÍGUEZ, A. (2013), "El mito de Domat". En: THORUD, C. F., ZALAQUETT, N. N., IRIBAREN, L. S. y SQUELLA, A. (eds.), Una vida en la Universidad de Chile: celebrando al Profesor Antonio Bascuñán Valdés, Santiago de Chile, Legal Publishing, pp. 263-350.

CHIASSONI, P. (2011), Técnicas de interpretación jurídica, Marcial Pons, Madrid.

CHIASSONI, P. (2012), “¿Son vinculantes los precedentes judiciales civiles?”. En: MORENO CRUZ, D. (comp.), Desencantos para abogados realistas, Bogotá, U. del Externado de Colombia, pp. 211-266.

DICIOTTI, E. (1999), Interpretazione della legge e discorso razionale, Giappichelli, Torino.

FALCÓN Y TELLA, M. J. (2010), La jurisprudencia en los Derechos romanos, anglosajón y continental, Marcial Pons, Madrid.

GUASTINI, R. (2004), La interpretazione dei documenti normativi, Giuffrè, Milano.

GUASTINI, R. (2016), La sintaxis del derecho, Marcial Pons, Madrid.

GUZMÁN BRITO, A. (1992), "La historia dogmática de las normas sobre interpretación recibidas por el Código Civil de Chile". En: AA.VV., Interpretación, integración y razonamiento jurídicos, Santiago de Chile, Editorial Jurídica de Chile, pp. 41-87.

GUZMÁN BRITO, A. (2011), Codificación del derecho civil e interpretación de las leyes, lustel, Madrid.

HERNÁNDEZ MARÍN, R. (1994), "Definiciones en el Derecho", Anuario de Filosofía del Derecho, XI, pp. 367-380.

IGARTUA, J. (2006), "La fuerza vinculante del precedente judicial", Isegoría, núm. 35, pp. $193-205$.

ITURRALDE SESMA, V. (1989): Lenguaje legal y sistema jurídico, Tecnos, Madrid.

ITURRALDE SESMA, V. (2013), "Precedente judicial", Eunomía, núm. 4., pp. 194201.

LAPORTA, F. (1997), "Vindicación del precedente judicial en España", Anuario de la Facultad de Derecho de la Universidad Autónoma de Madrid, núm. 1, pp. 267-278.

LLEWELLYN, K. (1950), "Remarks on the Theory of Appellate Decision and the Rules or Canons About How Statutes are to Be Construed", Vanderbilt Law Review, vol. 3, núm. 3, pp. 395-406.

MANJÓN-CABEZA OLMEDA, A. (2008), “¿Son vinculantes los acuerdos del pleno no jurisdiccional de la segunda del TS?", Revista Electrónica de Ciencia Penal y Criminología, núm. 10, pp. 02:01-02:25.

MARINONI, L. G (2013), Precedentes obligatorios, Palestra, Lima.

MARSHALL, J. (1993), "Trentatre cose che si possono fare con i precedenti", Ragion Pratica, núm 6, pp. 29-34.

MORESO J.J. y VILAJOSANA, J.M. (2004), Introducción a la teoría del derecho, Marcial Pons, Madrid.

NÚÑEZ VAQUERO, A. (2014a), "Ciencia jurídica: un mapa conceptual”. En: NÚÑEZ VAQUERO, A. (coord.), Modelando la ciencia jurídica, Lima, Palestra, pp. 1352.

NÚÑEZ VAQUERO, A. (2014b), "Dogmática jurídica”, Eunomía, núm. 6, pp. 245260.

NÚÑEZ VAQUERO, A. (2016a), "Breve ejercicio de teoría (realista) de la interpretación", lus et Praxis, vol. 22, núm. 1, pp. 129-164.

NÚÑEZ VAQUERO, A. (2016b), "Conceptos jurídicos dogmáticos: una aproximación ius-realista", Revus. Journal for Constitutional Theory and Philosophy of Law, núm. 28 (en prensa).

NÚÑEZ VAQUERO, A. (2016c), "Sin precedentes: una mirada escéptica a la regla del stare decisis", Doxa, núm. 38 (en prensa).

PÉREZ CARRILLO, A. (1974), "La definición legal”, Boletín Mexicano de Derecho Comparado, núm. 21, pp. 155-168. 
POZZOLO, S. (2011), Disposición vs, norma, Palestra, Lima.

RADIN, M. (1946), "The Trial of the Calf", Cornell Law Quaterly, vol. 32, pp.137-160.

SEARLE, J. (1997), La construcción de la realidad social, Paidos, Barcelona.

SCARPELLI, U. (1985), Contributo alla semantica del linguaggio normativo, Giuffrè, Milano.

TARELLO, G. (2013), La interpretación de la ley, Palestra, Lima.

TARUFFO, M. (2009), Páginas sobre justicia civil, Marcial Pons, Madrid.

VON WRIGHT, G. H. (1970), Norma y acción, Tecnos, Madrid.

WROBLESKI, J. (2008), Sentido y hecho en el derecho, Fontamara, México D.F.

ZANETTI, Jr. H. (2015), El valor vinculante de los precedentes, Raguel, Lima.

ZÚÑIGA URBINA, F. (2009), "Constitución y ley interpretativa. Algunas notas sobre una paradoja y peligros relativos a este tipo de ley", Ius et Praxis, vol. 15, núm. 2, pp. 255-281

ZÚÑIGA URBINA, F. (2011), "Control de constitucionalidad de autos acordados", Estudios constitucionales, vol. 9, núm. 1, pp. 389-418. 